\title{
Designing an intranet from scratch to sketch: experiences from techniques used in the
} IDEnet project

\section{Berndtsson, Johan}

\section{Published in:}

Proceedings of the 32nd Annual Hawaii International Conference on System Sciences, 1999. HICSS-32.

Link to article, DOI:

10.1109/HICSS.1999.772671

Publication date:

1999

Document Version

Publisher's PDF, also known as Version of record

Link back to DTU Orbit

Citation (APA):

Berndtsson, J. (1999). Designing an intranet from scratch to sketch: experiences from techniques used in the IDEnet project. In Proceedings of the 32nd Annual Hawaii International Conference on System Sciences, 1999. HICSS-32. IEEE. https://doi.org/10.1109/HICSS.1999.772671

\section{General rights}

Copyright and moral rights for the publications made accessible in the public portal are retained by the authors and/or other copyright owners and it is a condition of accessing publications that users recognise and abide by the legal requirements associated with these rights.

- Users may download and print one copy of any publication from the public portal for the purpose of private study or research.

- You may not further distribute the material or use it for any profit-making activity or commercial gain

- You may freely distribute the URL identifying the publication in the public portal 


\title{
Designing an Intranet from Scratch to Sketch: Experiences from Techniques used in the IDEnet Project
}

\author{
Johan Berndtsson \\ Center for Tele-Information, Technical University of Denmark \\ E-mail: berndtsson@cti.dtu.dk
}

\begin{abstract}
The choice of techniques to support system design is important in order to achieve a satisfactory result with regards to the quality of the future system. In the IDEnet development project we chose to work with techniques used within, or inspired by, three different research areas, Sociology, Participatory Design and Human Computer Interaction. The paper discusses the use of one technique from each of these research areas, ranging from 'scratch to sketch' in the development of an Intranet (IDEnet) at the Department of Computer Science and Business Administration (IDE), University College of Karlskrona/Ronneby in Sweden. The advantages and disadvantages for the use of each technique for system design are also discussed.
\end{abstract}

\section{Keywords}

Information Systems Design, Techniques, Intranet, Informal interviewing, Future Workshop with Democratic Dialogue, Card Sorting

\section{Introduction}

In the development of IDEnet ${ }^{1}$ we took advantage of techniques used within three different research areas, Sociology ${ }^{2}$, Participatory Design (PD) and Human Computer Interaction (HCI). However, the techniques are closely related in that one for example could easily argue that both recent $\mathrm{HCI}$ and especially PD are influ-

1 IDEnet is the Intranet of the Department of Computer Science and Business Administration (IDE), University of Karlskrona/Ronneby, Sweden.

${ }^{2}$ The technique presented in this paper (informal interviewing) has also been used in other research areas that utilizes ethnographic methods, such as e.g. Anthropology and Ethnology. enced by techniques used in Sociology, or for that matter that PD actually is a part of HCI. Also, and perhaps even more importantly, especially PD could be seen as a way of thinking about, and working with, the users rather than a specific research area. This way of thinking influence both our ways of acting on the field as ethnographers, and our ways of working as designers with the users in the design of the system. The plan for the development of the Intranet was to use a chain of techniques, each feeding the next. We began the project by performing informal interviews followed by a Future Workshop with Democratic Dialogue. The result from these activities were then used as input for the Card Sorting exercise which resulted in a first 'sketch' of the structure of the information on the Intranet. This could, in other words, be conceptualized as a first step towards a 'computerization' of a 'soft' system description.

Throughout 1997 an Intranet system to support course related activities at IDE was developed. One of the main problems the IDEnet project needed to address was the communication and information flow between the staff and the students. The existing methods of communication had students complaining about the information that they were given, or in some cases, not given. By creating an Intranet containing, among other things, information about courses such as schedules, syllabuses, exercises etc., the goal was to mitigate this problem. The domain at focus in this paper is therefore the administrative aspects of course related activities within the department.

This paper aims to describe and evaluate the use of three different techniques from different research areas, in an Intranet development project. By telling this story, about the design of an Intranet from 'scratch to sketch', the goal is to give successive projects of similar character a possibility to compare these conclusions both with their own experiences, and other techniques.

\section{The choice of informants}

For a system to become truly useful, actual experts on the task that the system is supposed to support need to be part of the design process. Both Bødker and Ehn discuss 
this within the field of Participatory Design, and in connection to what they call "the tools approach" or "the tool perspective":

"The intention is not to automate parts of the work process but to build computer based tools that are rooted in the craftsperson's original competence." (p. 123, [4])

"The idea is that new computer-based tools should be designed as an extension of the traditional practical understanding of tools and materials used within a given craft or profession. Design must therefore be carried out by the common efforts of skilled, experienced users and design professionals." (p. 57, [5])

The thought is that systems should be designed as tools, artifacts designed based on domain knowledge that therefore more easily will fit into the everyday work of the user and extend her capabilities. In the quotations above, both authors refer to the users as professionals in their work, and these experienced professionals working within the domain together with skilled analysts and designers are the only ones who can possibly know how their work best can be supported. In the IDEnet project, 25 persons (13 members of the staff and 12 students) were at some point involved in the development process. All of them had been working or studying within the organization for at least two years.

Through the work with the different techniques the students have been regarded as 'consumers' of course information, and the members of the staff as 'producers'. This division was made based on the assumption that the work with IDEnet of these two groups is so different that it would motivate designing two different interfaces.

In the following sections the use of the different techniques as well as the pros and cons for each technique in the development of IDEnet will be discussed.

\section{Informal interviewing}

Ethnographic techniques have been used for several decades within anthropology. During the last twelve years or so ethnographic methods have also been discussed and used to inform systems design (see for example [1; $2 ; 11-13 ; 22 ; 23])$.

"The ethnographer's task is to gain access to and knowledge of the social practices, knowledge, beliefs, attitudes and activities, etc., as exhibited by participants in some 'natural setting', and to present these in terms of a sociological account of a 'way of life' as organised by its participants.” (p. 127, [13])
Ethnographic techniques include observations, video and tape recordings, informal interviews etc. (e.g. [6;9]). However, due to time limits and the fact that no course managers were occupied with course preparations at that moment, we chose only to use informal interviewing to capture the work of the course managers at IDE.

One of the advantages of informal, or unstructured, interviewing is that few assumptions regarding what is important about the studied work are made at this early stage [3]. By discussing with, rather than interviewing, the informant about his or her work, the idea is that the researcher will learn what aspects of the work that are important, and therefore need further inquiry. In other words, the technique allows the informants to tell the ethnographers what's important about his or her job, rather than the other way around.

"A more or less complete list of questions - as in a structured interview - will hamper the analyst from following unanticipated yet interesting aspects and also make the interviewee passive since it will - correctly - give the impression that the analyst already made up his mind regarding what information is important and interesting.” (p. 122 (my translation), [24])

To summarize, working with a long list of very specific questions from the beginning might very well give you precise answers, but maybe not to the right questions.

Another aspect of informal interviewing is that it assumes that the informant's knowledge does not really resides 'within his or her head', but rather in the very culture of their work. Therefore the interview setting should be regarded as a key-issue. Blomberg et al. point this out by referring to the artifacts and the people, which are a natural part of the interviewee's world.

"Not only are the respondents more likely to feel comfortable in familiar surroundings, but they have access to people and objects that may figure into the talk as it unfolds. If a respondent is trying to describe an activity in which he participates, having available the artifacts, physical surroundings, and people that typically help shape the activity can be a resource for the talk." (p. 135, [3])

The interviews with the informants regarding their work with course information were therefore mostly held in the informants' own offices. When discussions about scheduling courses, choosing literature, the layout and contents of syllabuses, etc. came up, the work was easily demonstrated by the informant through the use of the available tools, such as calendars, syllabuses, and folders containing different kinds of information. 
In the IDEnet project we used informal interviewing as the first step, from scratch so to say, for three reasons. The first reason was that we wanted to learn more about the organization and the work of the staff in regards to the administration of courses. The second reason was that we wanted to use these meetings as an opportunity to introduce ourselves, our project, and also the technique Future Workshop with Democratic Dialogue, which was going to take place at a later time in the project. The third reason was that we wanted to get to know the users better, and give them a chance to get to know us, before the group activities were going to take place. In a previous project where Future Workshops were used, performed by one of the members of the IDEnet group, informal interviewing was suggested both as a way to make the acquaintance of the users, and to explain the motives behind the project. This was also recommended in their report in order to avoid unnecessary conflicts with, and worries among, the participants during the group activities (e.g. Future Workshops) [18].

Four students and six members of the staff were interviewed. One interview was scheduled with each informant and complementary questions were handled through E-mails or short visits. Each interview lasted between 30 and 60 minutes and was, for the staff, carried out in their respective offices. To facilitate the interviewing we used a checklist to help us cover certain aspects of the work during our interviews. These aspects were generally formulated as, e.g. "What tasks are important in your work?", "How are these tasks carried out?".

There were several different results from the informal interviews. To begin with, we learned a lot about the course administrative activities at IDE, and we got a chance to discuss our project and the following group activities with the participants. But the interviews also resulted in a short list of what information that the informants considered important in their work. This list however, came to grow substantially after the Future Workshop with Democratic Dialogue.

As we learned more about the work of administering and taking courses, we wanted to focus more specific on what problems and possibilities there were in their work, especially related to what support they had and what they lacked in their work. To do this we arranged a Future Workshop with Democratic Dialogue.

\section{Future Workshop with Democratic Dialogue}

Future Workshop with Democratic Dialogue is a technique from the Participatory Design research area which is based upon the assumption that a high degree of user involvement in the design process will result in both a higher product quality and a more democratic change process at the workplace (e.g. [4; 25]):

"Two important features of participatory design shape its trajectory as a design strategy. The political one is obvious. Participatory Design raises questions of democracy, power and control at the workplace. In this sense it is a deeply controversial issue, especially from a management point of view. The other major feature is technical-its promise that the participation of skilled users in the design process can contribute importantly to successful design and high-quality products." (p. 41, [5])

Aside from the expected rise in product quality from having users participating in the design process, we also believe that the chances of the system being accepted by the users increase if the users have participated in the development themselves.

Future Workshop was originally developed by Jungk and Müllert [15] for a citizens group who, in spite of limited resources, wanted to influence the decisionmaking process in public questions. Kensing suggested that the technique could be used in system development (Participatory Design) [16], and together with HalskovMadsen he later used it as an organizational frame, together with what they called Metaphorical Design, as a linguistic tool to enable participants to explain and discuss their own work situation [17]. Friis then took the technique even further by combining it with Democratic Dialogue [7], a technique developed by Gustavsen [10] that can be conceptualized as a way to facilitate a democratic collaboration between the participants in a workshop. The technique is based on a set of rules that are used by the facilitators to guide the discussion, mainly to ensure that everybody's voice is heard. The purpose of this combined technique is to, through democratic discussions with the users, illustrate different problems in the current work situation, generate visions about the future of the work, and define a procedure for how some of these visions can be implemented.

Phase 1 - Critique: The critique phase aims at identifying and making visible the problems in the current work situation, and has the form of a structured brainstorming session where the participants focus on specific issues that they find problematic. The participants must themselves summarize their respective ideas on a large sheet of paper. The reason for making them write their own suggestions is that ideas and opinions easily are misinterpreted and thus might be documented differently than intended if the originator himself/herself is not holding the pen. To accommodate less talkative participants, the length of the talk for each participant should be limited, and no participant is allowed to criticize anyone else's idea or opinion, nor do they have to motivate 
their opinions in any way. The facilitator decides when the phase is finished, and to conclude the critique part of the exercise everyone helps to categorize the different opinions into different categories.

Phase 2 - Fantasy: The second phase aims at stimulating the participants' fantasy, and have them put forward visions about how they would like their work to be. To stimulate the participants' fantasy different warm-up activities such as e.g. asking the participants to draw their own dream workplace five years from now is often used. After warm-ups the fantasy phase is performed in a similar manner as the critique phase, no fantasies are regarded as unrealistic or can be criticized. In the end of the brainstorming a vote is arranged to sort out the best ideas. One way of performing the vote is using small colored stickers, each participant gets e.g. five stickers to divide as he or she like on the different fantasies suggested. Finally, the 'best' fantasies are sorted out and rewritten to become a statement from the whole group.

Phase 3 - Implementation: The third, and last phase, focuses on forming goals and generating concrete suggestions regarding how these goals could be achieved. The result from the fantasy phase serves as a natural starting point. Plans for the implementation is made in the form of a division of responsibilities, and distribution of tasks between the different participants. This way the Future Workshop can be regarded as being more than a 'one time happening', but rather a start of a change process in the work situation for the participants.

By using Future Workshops with Democratic Dialogue with four members of the staff and three students our hopes were to learn more about what in today's work situation the students and the staff find problematic and also how they would like it to be in the near future. However, this workshop, as well as previously held workshops of this kind, indicated that several aspects of this technique are quite problematic.

First, the opening critique suggested by a participant often seems to set the direction of most of the following. E.g. if the first statement is about problems with the booking of lecture rooms, chances are that a large part of the following discussion will be too. In order to uncover more possible directions of the discussion before focusing on one, a choice was made to do the first part of the critique phase as an individual exercise where each participant was given a stack of Post-IT ${ }^{\circledR}$ notes on which he or she was told to write the critique that s/he wanted to put forward. About five minutes later the participants ware asked to present their critique to the rest of the group by placing their Post-IT ${ }^{\circledR}$ notes on a whiteboard. The presentation of the critiques, in turn, generated more ideas regarding problematic issues regarding the work situation. Grouping the critique into different categories finished the phase. Thanks to the Post-IT ${ }^{\circledR}$ notes this came to be quite an interesting activity where most of the participants were engaged in discussions including adding, moving, grouping and regrouping the notes as they saw appropriate.

Second, the warm-up activities sometimes seem to break the participants' concentration, taking their mind of the recently discussed problems. Thus, moving on directly to the second phase is sometimes preferable. Since there already were critiques within several different areas, that were being discussed, we continued to work in groups during this phase without any individual activities as in the first phase. Only now the discussion was concentrated on fantasizing about the work, and inevitably on grand solutions for the presently problematic situations. This time the fantasies were written directly on a whiteboard, and voting took place using differently colored pens to mark the different individuals' preferred alternatives. The 'best' alternatives were left as they first were written.

Third, the implementation phase is often problematic. For us it was neither financially possible to use the informants themselves in the design of IDEnet, nor do we believe that this always is a useful approach. It can be a great benefit to let people who are affected by the changes inferred through the implementation of a new system participate, but when it comes to practice few people have the time or energy it takes to complete the tasks laid upon them. Thus all suggestions introduced in this phase had to be implemented by the project group. This phase was therefore carried out as an open discussion about the 'best' fantasies, and how these could be realized. Fantasies regarding support systems was deliberately more elaborated than others were, since this was the main interest for the IDEnet group.

Even though Future Workshop with Democratic Dialogue has its weaknesses, the results from it, if carried out with the above-suggested changes, can be quite useful. It's a good way to learn about existing problems within the organization. In our case, an interesting aspect was that the list of critique from the different groups (the students and the staff), were very much alike. It seemed, as the staff was very much aware of the students' problems, and solving these were a heart issue for both the students as well as the staff. Also, through their fantasies and visions something is learned regarding in what direction the people working within the organization are striving, what they think is important and what's not. Even though many of these fantasies often are impossible to implement, a discussion about this matter offers a possibility to learn about both the students' and the staffs' long term visions. In our case the actual system designers were present and were thus more able to reach an understanding of the purpose of the new system than if they had been given a requirement specification to follow. 
From a practical point of view the results from the Future Workshop mainly served as input for the Card Sorting regarding what information, and what 'features', in a future system that could be useful to the participants.

\section{The Card Sorting technique}

In Internet and Intranet systems ease of navigation, or 'navigability', has drawn a lot of interest. Several researchers have, however, pointed out that navigating hypermedia is a difficult task $[14 ; 19]$. Therefore, starting from a 'mess' of requested information 'chunks' and features, which was one of the results from the interviews and the Future Workshop, we needed to create IDEnet for an understandable information structure. For this purpose we turned to a technique known as Card Sorting (p. 127, [20], [21]).

Card Sorting is often "used to discover users' mental model of an information space" [21], e.g. for structuring information in computer applications such as pull-down menus, information databases and World Wide Web services. By sorting cards representing different 'features' or 'chunks' of information into different piles the user produces a possible information structure for the computer system at focus. Furthermore, although references between the techniques seem to be missing, the Card Sorting technique resembles what Schmidt and Carstensen (p. 126, [24]), by pointing at work by Gammack and Young [8], refer to as "Concept Sorting" (my translation). A technique used in work analysis to structure large sets of domain specific concepts.

The technique itself is best explained through describing the preparation, the actual Card Sorting which is performed through a series of steps, and finally the analysis of the result.

Before the actual Card Sorting can commence, cards with concepts relevant in the user's domain written on one side must be prepared. During the actual Card Sorting session, the cards can be used in the following steps:

1. Place the cards in random order on a table with the concepts facing upwards.

2. Ask the user to sort the cards into piles of similarity, i.e. which concepts he or she thinks belong together.

3. If there are many cards, ask the user to group the piles into larger groups without dividing the original piles.

4. Ask the user to name the different groups.

5. Make a note of which cards were placed in which pile and which piles ended up in which group. Also, document the names of the groups.

The results from each session are several groups of cards with different names. To analyze these groups either use 'eyeballing' or a similarity matrix [21]. The technique is based on the assumption that if two different cards are grouped together by a large percentage of the different users, the concepts should probably be grouped together in the system. From these results we finally derive a grouping that we think represents what could be called a common opinion. This structure can then be used as a starting point in the design of the new information system. In our case, the results from the use of this technique were used for structuring concepts referring to the different 'chunks' of information and 'features' requested in the first prototype, or 'sketch', of IDEnet.

An important issue in Card Sorting is to use concepts that the users are familiar with, use their language so to say. In their description of the technique, Nielsen and Sano used brainstorming by the developers to obtain the concepts. Considering the fact that they were creating an Intranet for their own company, that might be acceptable, but, extracting the concepts through interviews, discussions or workshops is definitely recommended when designing for most users.

In order to find out how the users wanted the interface of the new system to be structured, we analyzed the results from the students (8 participants) and the staff (7 participants) separately from each other. By doing so we aimed to develop a 'producer interface' and a 'consumer interface' for the system. This separation was made since they actually are two very different target groups, with different tasks, and because they will use two completely different 'sides' of the system. The prototype was, however, not an exact copy of the results from the Card Sorting. A few of the resulting combinations between different concepts were, based upon the knowledge gained through the informal interviews and the Future Workshop with Democratic Dialogue, known to be 'incorrect'. And also, the names on some the groups that the participants in the Card Sorting sessions had provided were very different from each other even when the contents of the groups were very similar. We ended up trying to name these groups ourselves.

The result from the use of the Card Sorting technique should, according to its underlying theory, provide a view of how the 'average user' would prefer the information to be structured. The problem is that the 'average user' does not exist, and thus there is an obvious risk that none of the users will actually like the system. During our Card Sorting sessions we noted that besides the unavoidable individual variances, it seemed as though the cards could be organized according to different categorization 'themes'. This was especially obvious among the staff where many participants chose to do either a 'chronological' (e.g. things to do before, during or after a course), or a 'responsibility based' (tasks connected to the roles of course manager, teacher etc.) grouping of the concepts. The problem here is that if the result from this 
technique is processed using a similarity matrix the themes are mixed into a mess that indirectly suggests that issues of work sequence are directly connected to the way responsibilities are distributed among the staff at IDE, which is not the case.

Nielsen addresses this question by pointing out that the Card Sorting technique, as well as all techniques, is supposed to be used with care and its results should only be regarded as help for the designer, who often has to act against the results of the test in order to create a good design [Personal conversation with Nielsen, ACM CHI97, Atlanta GA]. Be this as it may the point is that the Card Sorting technique, as well as any other technique that relies on a conception of a 'common' mental model among users, always should be treated as very unreliable. Only where an overwhelming similarity between the results from different users is found can the result be used as a foundation for design. And, interesting as it seems, if the result is so overwhelming there would be little need for statistical calculations, or even for visualizing the result through e.g. a similarity matrix. A guideline should therefore be to rely on the result only if it is so obvious that you can see it with your own eyes without processing the results in any way.

In spite of the critique raised above, handled with care the resulting structures can be quite useful. And also, if you ask people why they grouped the cards the way they did after each exercise you might not only be able to choose a theme that suit most users, but you may also be clear to the rest of the users regarding on what theme the grouping is based.

\section{Conclusions}

The set of techniques presented in this paper by no means represent a uniform approach to system design, or to work analysis as a way of informing systems design, which I believe these techniques also could be described as. Rather they represent a combination of experiences from radically different perspectives. But since systems development is about successfully moving from 'soft' descriptions of work to 'hard' descriptions of systems, the techniques to support this work should also support this move. Each technique here complements the others to build a system design in ways that I believe techniques from one single research area could not. The informal interviewing serves as an excellent way to learn about the organization and the work performed, and also about the questions that are relevant to ask. The Future Workshop with Democratic Dialogue serve as a step closer to the design of a system, identifying problems in the present work situation, and just as important, possible solutions to these problems. And finally, Card Sorting is used for the first step towards translating the 'soft' and ambiguous descriptions of work, obtained from the informal interviewing and the Future Workshop with Democratic Dialogue, into a computerized system.

Another important issue in the use of these techniques is the consequent use of materials that allow the users to easily try different ideas. In both the critique phase of the Future Workshop with Democratic Dialogue, as well as in the Card Sorting, Post-It ${ }^{\circledR}$ notes were used, allowing the users to move the notes around and try different groupings before settling on the one they preferred.

In this paper a set of techniques have been described and evaluated in connection to the development of an Intranet. It is my hope that others, by comparing these descriptions with their own experiences, or other techniques, will find ways to work with system development from 'scratch to sketch' that are useful to them.

\section{Acknowledgements}

I would like to thank IDE for giving me the opportunity to work with this project. Thanks to the IDEnet group, especially Mattias Göransson and Anja Klint, and to all the informants/participant in the project. Bo Helgeson (University of Karlskrona/Ronneby, Sweden) and Maria Normark (Technical University of Denmark) have been most helpful with comments on a draft of this paper.

\section{References}

1. Anderson, R. J.: 'Representations and requirements: The value of ethnography in system design,' HumanComputer Interaction, vol. 9, 1994, pp. 151-182.

2. Anderson, R. J.: 'Work, ethnography, and system design,' in A. Kent and J. G. Williams (eds.): The Encyclopedia of Microcomputing, vol. 20, Marcel Dekker, New York, 1997, pp. 159-183.

3. Blomberg, J., J. Giacomi, A. Moscher, and P. SwentonWall: 'Ethnographic Field Methods and Their Relation to Design,' in D. Schuler and A. Namioka (eds.): Participatory Design: Principles and Practices, Lawrence Erlbaum Associates, Hillsdale, New Jersey, 1993, pp. 123-155.

4. Bødker, S.: Through the Interface: A human activity approach to user interface design, Lawrence Erlbaum Associates, Hillsdale, New Jersey, 1991.

5. Ehn, P.: 'Scandinavian Design: On participation and skill,' in D. Schuler and A. Namioka (eds.): Participatory Design: Principles and Practices, Lawrence Erlbaum Associates, Hillsdale, New Yersey, 1993, pp. 41-77.

6. Ely, M., M. Anzul, T. Friedman, D. Gardner, and A. McCormack Steinmetz: Doing Qualitative Research: Circles in Circles, The Falmer Press, New York, 1991.

7. Friis, S.: 'The PROTEVS Approach: A short presentation of background, principles and methods,' $A I$ \& Society, no. 9, 1995. 
8. Gammack, J. G., and R. M. Young: 'Psychological Techniques for Eliciting Expert Knowledge,' in M. A. Bramer (ed.) Research and Development in Expert Systems, Cambridge University Press, Cambridge, 1985, pp. 105-112.

9. Goodwin, C.: 'Recording Human Interaction in Natural Settings,' Pragmatics - Quarterly Publication of the International Pragmatics Association, vol. 3, no. 2, 1993, pp. 181-209.

10. Gustavsen, B.: Theory of Communication, Action Research and the Restructuring of Working Life, Arbetslivscentrum, Stockholm, Sweden, 1992.

11. Hughes, J. A., V. King, T. Rodden, and H. Andersen: 'Moving Out from the Control Room: Ethnography in System Design,' in R. Furuta and C. Neuwirth (eds.): Proceedings on the Conference on Computer Supported Cooperative Work, CSCW'94, , ACM Press, 1994.

12. Hughes, J. A., D. Randall, and D. Shapiro: 'Faltering from ethnography to design,' in J. Turner and R. Kraut (eds.): CSCW '92. Proceedings of the Conference on Computer-Supported Cooperative Work, Toronto, Canada, 31 October 4 November, 1992, ACM Press, New York, 1992, pp. 115-122.

13. Hughes, J. A., D. Randall, and D. Shapiro: 'From ethnographic record to system design: Some experiences from the field,' Computer Supported Cooperative Work (CSCW). An International Journal, vol. 1, no. 3, 1993, pp. 123-141.

14. Höök, K., M. Sjölinder, and N. Dahlbäck: 'Individual Differences and Navigation in Hypermedia,' in Proceedings of the Eight European Conference on Cognitive Ergonomics (ECCE-8), , 1996.

15. Jungk, R., and N. Müllert: Future Workshops: How to create desireable futures, Institute for Social Inventions, London, UK, 1987.

16. Kensing, F.: 'Generation of Visions in Systems Development,' in P. Docherty at al. (eds.): Systems Design for Human Productivity - Participation and beyond, North-Holland Publishing, Amsterdam, 1987, pp. 285-301.

17. Kensing, F., and K. Halskov-Madsen: 'Generating Visions: Future Workshops and Metaphorical Design,' in J. Greenbaum and M. Kyng (eds.): Design at Work, Lawrence Erlbaum Associates, Hillsdale, New Jersey, 1991.

18. Klint, A, and A. Lindblom: Participatory Design: En diskussion kring systemutveckling med brukarmedverkan, Paper for a course in Participatory Design, University of Karlskrona/Ronneby, Ronneby, Sweden, 1997.

19. Nielsen, J.: 'The Art of Navigating Through Hypertext,' Communications of the ACM, vol. 33, no. 3, 1990, pp. 296-310.

20. Nielsen, J.: Usability Engineering, Academic Press, Boston, 1993.

21. Nielsen, J., and D. Sano: 'SunWeb: User Interface Design for Sun Microsystem's Internal Web, (http://www.ncsa.uiuc.edu/SDG/IT94/Proceedings/HCI/n ielsen/sunweb.html), in Electronic Proceedings of the Second World Wide Web Conference '94: Mosaic and the Web, , 1994.

22. Randall, D., J. A. Hughes, and D. Shapiro: 'Using Ethnography to Inform Systems Design,' Journal of Intelligent Systems (UK), vol. 4, no. 1-2, 1994, pp. 9-28.

23. Rose, A., B. Shneiderman, and C. Plaisant: 'An Applied Ethnographic Method for Redesigning User Interfaces,' in DIS'95, Conference proceedings on Designing interactive systems: processes, practices, methods \& techniques, , ACM Press, 1995.

24. Schmidt, K., and P. Carstensen: Arbejdsanalyse. Teori og praksis, Ris $\varnothing$ National Laboratory, DK-4000 Roskilde, Denmark, June, 1990Ris $\varnothing-M-2889]$.

25. Schuler, D., and A. Namioka (eds.): Participatory Design: Principles and Practices, Lawrence Erlbaum Associates, Hillsdale, New Jersey, 1993. 